\title{
Detection of Chlamydia pneumoniae and Chlamydia psittaci in sputum samples by PCR
}

\author{
C Y W Tong, M Sillis
}

\begin{abstract}
Aims-To use the polymerase chain reaction (PCR) to detect Chlamydia pneumoniae and Chlamydia psittaci in sputum samples.
\end{abstract}

Methods-A nested PCR was developed, the first stage of which amplified DNA from both $C$ pneumoniae and $C$ psittaci while the second stage targeted specifically at $C$ pneumoniae, allowing the two species to be differentiated. The primers were designed not to amplify sequences from $C$ trachomatis. A panel of 26 sputum samples from patients with community acquired pneumonia evaluated previously by enzyme linked immunosorbent assay (ELISA), direct immunofluorescence (DIF), and culture was tested blind by PCR. Most of these specimens also had accompanying serial serum samples which were tested for species specific antibodies using microimmunofluorescence (micro-IF).

Results-PCR detected $C$ pneumoniae DNA in 10 of the 26 samples and $C$ psittaci DNA in four. There was good concordance between ELISA, DIF, micro-IF and PCR in the $C$ pneumoniae group. Two of the $C$ psittaci identified by PCR were labelled $C$ pneumoniae by DIF but the PCR results were supported by serology or a history of bird contact. Of the PCR negative group: six were true negative results; two contained $C$ trachomatis. There were four discrepant results.

Conclusions-The data suggest that PCR is effective in the detection of $C$ pneumoniae. The sensitivity for $C$ psittaci is inevitably lower due to the strategy taken but specificity seemed to be good.

(f Clin Pathol 1993;46:313-317)

Chlamydia pneumoniae and Chlamydia psittaci are important causes of lower respiratory tract infections. The reported prevalence of $C$

Table 1 Sequence and position of the primers on the ompA gene of $C$ pneumoniae

\begin{tabular}{llc}
\hline Primers & Sequence & Positions \\
\hline External & 333 base pair products & \\
CP1(sense) & 5' TTA CAA GCC TTG CCT GTA GG 3' & $61-80$ \\
CP2(anti-sense) & 5' GCG ATC CCA AAT GTT TAA GGC 3' & 373-393 \\
Internal & 207 base pair products & \\
CPC(sense) & 5' TTA TTA ATT GAT GGT ACA ATA 3' & 100-120 \\
CPD(anti-sense) & 5' ATC TAC GGC AGT AGT ATA GTT 3' & 286-306 \\
\hline
\end{tabular}

pneumoniae in community acquired pneumonia has ranged between $10-20 \% .^{1-3} C$ psittaci has remained an important pathogen in the United Kingdom and has been associated with the import of psittacine birds ${ }^{4}$ and with domestic poultry. ${ }^{5}$ Despite the importance of these two organisms, early and reliable methods for laboratory diagnosis are not available. Isolation from clinical specimens is difficult for $C$ pneumoniae 6 and hazardous for $C$ psittaci. $^{7}$ Though well established for $C$ trachomatis, ${ }^{89}$ the value of enzyme linked immunosorbent assay (ELISA) and direct immunofluorescence (DIF) for detecting these two organisms in respiratory samples has had only a preliminary evaluation. ${ }^{1011}$ Due to the heterogeneity of $C$ psittaci as a group, no species specific reagent is available, making species differentiation difficult. Serology, particularly microimmunofluorescence (micro-IF), has been the mainstay of diagnosis, but the retrospective nature of this test, due to the late appearance of species specific antibodies, has made it unhelpful in clinical management.

Several groups have explored the possibility of detecting $C$ pneumoniae or $C$ psittaci using the polymerase chain reaction (PCR). ${ }^{12-14}$ However, these reports provided very little information on the use of PCR on clinical specimens, particularly on sputum samples from patients with pneumonia. A method to detect and differentiate $C$ pneumoniae and $C$ psittaci in sputum samples using PCR has been developed.

\section{Methods}

The major outer membrane protein genes (ompA) of $C$ pneumoniae and $C$ psittaci were chosen as the target for amplification in a nested PCR. All primers were synthesised using an oligonucleotide synthesiser (Applied Biosystems). The outer primers (table 1) amplified a 333 base pair product from both organisms. The primers were chosen so as not to amplify the ompA gene of $C$ trachomatis. One of the internal primers, designated CPD, was located in a variable domain of the ompA gene and was specific for $C$ pneumoniae. ${ }^{1516}$ Hence only the first stage product from $C$ pneumoniae was exponentially amplified to yield the 207 base pair second stage product, allowing the two organisms to be differentiated.

Sputum samples were prepared and concentrated as described before. ${ }^{17}$ Before PCR, the concentrated specimens were diluted ten- 
fold in PCR buffer $(10 \mathrm{mM}$ TRIS- $\mathrm{HCl}, \mathrm{pH}$ $8.3,50 \mathrm{mM} \mathrm{KCl}, 1.5 \mathrm{mM} \mathrm{MgCl}_{2}, 0.1 \%$ Triton $\mathrm{X}-100)$ and digested with proteinase $\mathrm{K}(60 \mu \mathrm{g} / \mathrm{ml})$ at $55^{\circ} \mathrm{C}$ for 60 minutes. After digestion, proteinase $\mathrm{K}$ was inactivated by heating to $100^{\circ} \mathrm{C}$ for 10 minutes and the samples were cooled on ice. Ten microlitres of the treated samples were subjected to PCR under mineral oil overlay in the same PCR buffer with $0.4 \mu \mathrm{M}$ each of CP1 and CP2 primers (table 1), $200 \mu \mathrm{M}$ each of dATP, dTTP, dCTP and dGTP (Pharmacia) and 2.5 units of Taq DNA polymerase (Northumbria biological laboratories). Amplification was done with a thermocycler (Perkin-Elmer) using the technique of "Touchdown" $\mathrm{PCR}^{18}$ in which the annealing temperature was lowered $1^{\circ} \mathrm{C}$ every two cycles from $65^{\circ} \mathrm{C}$ until touching down to $55^{\circ} \mathrm{C}$ at which temperature 20 more cycles were performed. The denaturation temperature and the extension temperature were constant at $94^{\circ} \mathrm{C}$ and $72^{\circ} \mathrm{C}$, respectively. The holding time at each temperature was 1 minute.

The PCR products amplified by the outer

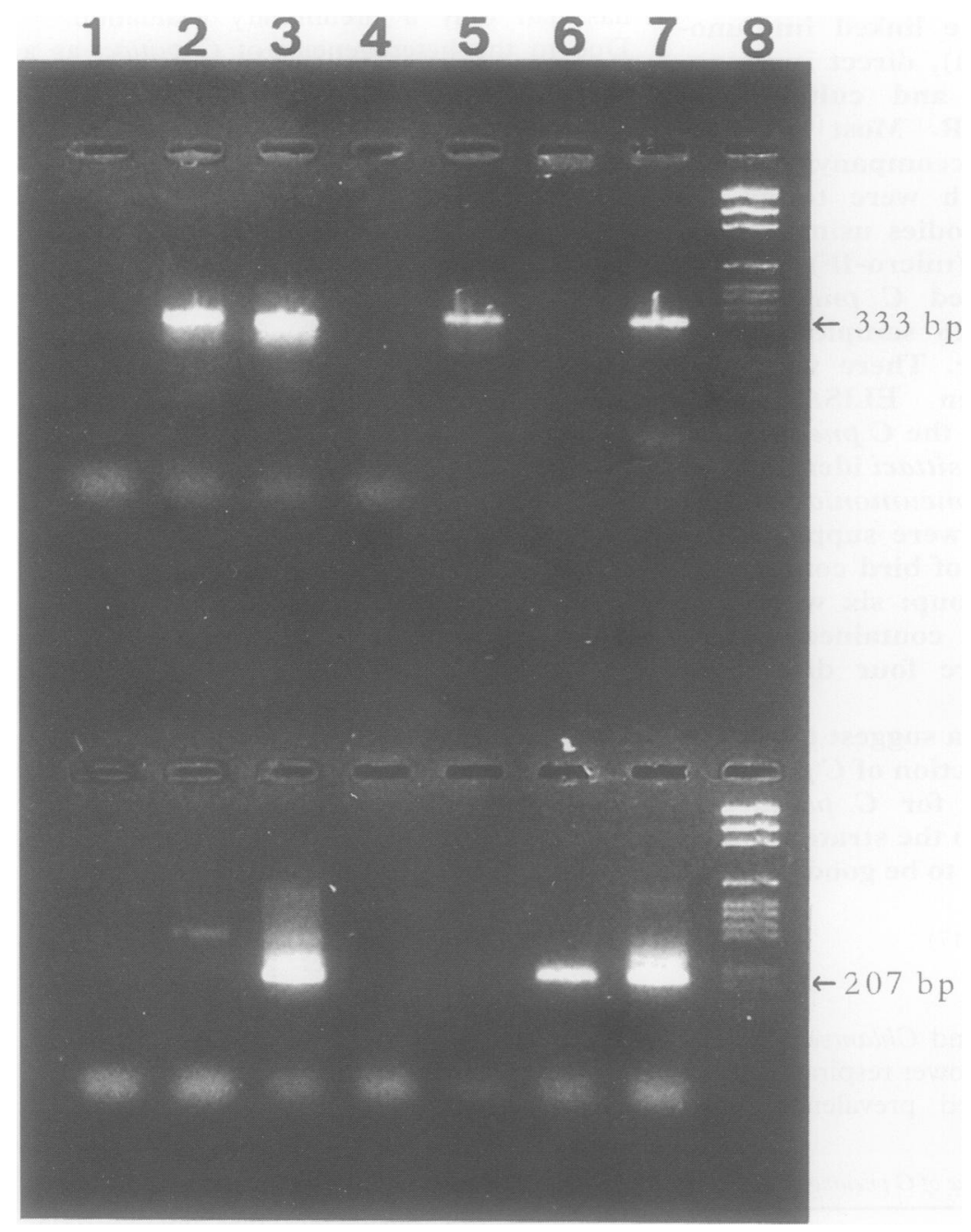

Agarose gel electrophoresis of PCR products-first stage in upper part and second stage in lower part of the gel. Lanes 1-3: tissue culture fluid (1 C trachomatis serovar A strain $S A 1 ; 2 C$ psittaci strain 33L-human; $3 C$ pneumoniae strain IOL 207). Lanes 4-7: sputum samples ( 4 case 18 - negative; 5 case $13-C$ psittaci; 6 case $2-C$ pneumoniae, low positive; 7 case 4-C pneumoniae, strong positive). Lane 8 pGEM molecular size marker (Promega). primers were diluted 10 times in water, and $10 \mu \mathrm{l}$ was transferred to a PCR reaction mix for amplification in a second stage using the inner primers. The PCR reaction mix was the same as before except that $1 \mu \mathrm{M}$ each of the primers CPC and CPD (table 1) were used and the $\mathrm{MgCl}_{2}$ concentration was increased to $3 \mathrm{mM}$. The second stage PCR consisted of 30 cycles of $94^{\circ} \mathrm{C}, 50^{\circ} \mathrm{C}, 72^{\circ} \mathrm{C}$ each for 1 minute. Both the first and second stage products were analysed in 3\% agarose gel electrophoresis (Seakem LE:Nusieve GTG 1:3, FMC Bioproducts) with ethidium bromide staining by standard techniques. ${ }^{19}$ PCR was performed in the Virology Department of Royal Victoria Infirmary, Newcastle Upon Tyne which did not provide routine chlamydial diagnostic service, and no cloned chlamydial genetic materials were handled in the laboratory. All samples were tested blindly and repeated at least twice before reporting. Throughout the procedures, standard precautions were adopted to avoid cross-contaminations. ${ }^{20}$

The above methods were initially evaluated and optimised using tissue culture materials from the Institute of Ophthalmology, London. All the serovars of $C$ trachomatis, 10 strains of $C$ psittaci (three human, four feline, one avian, one ovine, one guinea pig) and two strains of $C$ pneumoniae (IOL 207 and TW 183) were tested. Twelve species of bacteria (Streptococcus pneumoniae, Haemophilus influenzae, Staphylococcus aureus, Neisseria lactamica, Escherichia coli, Klebsiella oxytoca, Proteus mirabilis, Pseudomonas aeruginosa, Salmonella typhimurium, Streptococcus pyogenes, Enterococcus faecalis, Mycoplasma pneumoniae) were included to rule out possible cross-reactions. The sensitivity of the test was assessed by comparing PCR results with elementary body counts based on DIF

Twenty six sputum samples from patients with community acquired pneumonia, examined initially for evidence of chlamydial infections using ELISA (IDEIAIII, Dako Diagnostics), DIF, and cell culture, were selected for testing using the described PCR method. Most of these samples had accompanying serial serum samples which were tested by micro-IF in the Institute of Ophthalmology, London.

DIF was performed on all samples using a genus specific monoclonal antibody (Imagen, Dako Diagnostics). Presence of three or more EBs with the characteristic morphology, size, and fluorescence was regarded as a positive result. Some of the samples were also analysed with species specific monoclonal antibodies ( $C$ trachomatis-Syva, $C$ pneumoniae Cellabs). Specimens positive for genus specific antigen but negative for species specific antigen were interpreted as $C$ psittaci. Cell culture was performed using McCoy cells as described ${ }^{17}$ and stained with the above monoclonal antibodies. Micro-IF was performed as described. ${ }^{21}$ A single titre greater than $1 / 256$, positive IgM or a fourfold shift in titre were taken as diagnostic of recent infection. A stable titre of $1 / 256$ in a patient with 
Table 2 Combined results of all the tests done on the panel of 26 specimens

\begin{tabular}{|c|c|c|c|c|c|c|c|}
\hline \multirow{2}{*}{$\begin{array}{l}\text { Case } \\
\text { No }\end{array}$} & \multirow{2}{*}{$\begin{array}{l}\text { Bird } \\
\text { contact }\end{array}$} & \multirow[b]{2}{*}{ ELISA } & \multicolumn{2}{|l|}{$D I F$} & \multirow[b]{2}{*}{ Culture } & \multirow[b]{2}{*}{ Micro-IF } & \multirow[b]{2}{*}{$P C R$} \\
\hline & & & Genus & Species & & & \\
\hline 1 & No & + & + & $C$ pneumoniae & - & $C$ pneumoniae 1:256 & $C$ pneumoniae \\
\hline 2 & NK & ++ & + & ND & - & $C$ pneumoniae $1: 256 \rightarrow 1: 64$ & Cpneumoniae \\
\hline 3 & Yes & +++ & + & $C$ pneumoniae & $\begin{array}{l}\text { C pneumoniael } \\
C \text { psittaci }\end{array}$ & $C$ pneumoniae $1: 512$ & C pneumoniae \\
\hline 4 & No & ++ & + & $C$ pneumoniae & - & $C$ pneumoniae 1:256 & C pneumoniae \\
\hline 5 & No & $++t$ & + & C pneumoniae & - & C pneumoniae IgM + & C pneumoniae \\
\hline 6 & No & & + & ND & - & No significant titre & C pneumoniae \\
\hline 7 & NK & +++ & + & $C$ pneumoniae & - & No significant titre & $C$ pneumoniae \\
\hline 8 & NK & + & + & C pneumoniae & - & $\begin{array}{c}C \text { pneumoniae/C psittaci } \\
\text { both }>1: 256\end{array}$ & $C$ pneumoniae \\
\hline 9 & No & + & + & $C$ pneumoniae & - & Not available & $C$ pneumoniae \\
\hline 10 & NK & + & + & $C$ pneumoniae & - & $C$ pneumoniae IgM + & C pneumoniae \\
\hline 11 & Yes & \pm & + & ND & - & No significant titre & $C$ psittaci \\
\hline 12 & Yes & ++ & + & $C$ psittaci & $C$ psittaci & $C$ psittaci $1: 16 \rightarrow 1: 256$ & $C$ psittaci \\
\hline 13 & Yes & +++ & + & Cpneumoniae & - & $C$ psittaci $1: 2048$ & $C$ psittaci \\
\hline 14 & Yes & + & + & $C$ pneumoniae & - & No significant titre & $C$ psittaci \\
\hline 15 & NK & - & - & 1 & ND & No significant titre & - \\
\hline 16 & NK & - & - & I & ND & No significant titre & - \\
\hline 17 & NK & - & - & I & ND & No significant titre & - \\
\hline 18 & NK & - & - & I & ND & No significant titre & - \\
\hline 19 & NK & + & - & I & ND & No significant titre & - \\
\hline 20 & NK & + & - & 1 & ND & No significant titre & - \\
\hline 21 & Yes & \pm & + & IND & C trachomatis & No significant titre & - \\
\hline 22 & No & \pm & + & C trachomatis & C trachomatis & No significant titre & - \\
\hline 23 & Yes & + & + & $C$ psittaci & - & Not available & - \\
\hline 24 & NK & $+t$ & + & ND & - & No significant titre & - \\
\hline 25 & Yes & $+\star$ & $+\star$ & ND & - & $\begin{array}{c}C \text { pneumoniae/C psittaci } \\
\text { both IgM + }\end{array}$ & —* \\
\hline 26 & NK & + & + & $C$ psittaci & - & $C$ psittaci $1: 4096$ & - \\
\hline
\end{tabular}

ND $=$ Not done.

NK $=$ Not known.

IND = Indeterminate.

* Sputum sample received 6 months after serum samples.

relevant clinical details and no other obvious aetiological cause was taken as suggestive of recent infection.

\section{Results}

All the 10 strains of $C$ psittaci tested produced a first stage product of the expected size with no second stage amplification. The two $C$ pneumoniae strains were amplified in both the first stage and the second stage also with products of expected sizes (figure). None of the $C$ trachomatis serovars and none of the other bacteria tested produced amplifications. Based on elementary body counts by DIF, the first round of PCR detected between 5 to 10 particles and the second round detected less than one elementary body of $C$ pneumoniae.

Of the 26 sputum samples, PCR identified 10 as containing $C$ pneumoniae, four as containing $C$ psittaci, and 12 as negative (table 2). Seven of $10 C$ pneumoniae strains identified by PCR were substantiated by serological evidence suggesting recent $C$ pneumoniae infection and all had evidence of chlamydial presence by ELISA or DIF. Species specific DIF identified eight as $C$ pneumoniae. Chlamydiae were isolated from case 3 but the organism failed to grow on subsequent passage and the isolate was consequently not identified.

PCR identified $C$ psittaci in specimens from four patients (cases 11-14). Two of these had serological evidence of recent $C$ psittaci infection. The sputum from case 12 was also positive by culture for $C$ psittaci. Species differentiation by DIF suggested that strains from cases 13 and 14 were $C$ pneumoniae rather than $C$ psittaci. However, both patients had close bird exposure. In case 13 the serological profile taken over a four week period after onset of illness showed a rise in $C$ psittaci titre up to $1 / 2048$, whereas the corresponding titre of $C$ pneumoniae was only $1 / 64$. The blood sample of case 14 was taken too early to have clinically important species specific antibody titres.

Specimens from cases $15-18$ had no evidence of chlamydial infection by ELISA or DIF and no clinically important micro-IF results. PCR identified all four as negative. Cases 19 and 20 were judged to be falsely positive by ELISA since there was no other evidence of chlamydial infection. Cases 21 and 22 were cases of $C$ trachomatis. They were negative by PCR as expected since the strategy used will not amplify DNA from $C$ trachomatis. It was difficult to ascertain whether the discrepant results in cases 23-25 represented PCR false negatives or false positive ELISA and DIF. Serum was unavailable from case 23, although he gave a history of contact with a sick parrot. Case 24 died within the first week of illness, and the acute serum did not have clinically important micro-IF titre. Case 25 had IgM antibodies reacting with both $C$ psittaci and $C$ pneumoniae. However, the sputum sample from this patient was received six months after the blood sample when the patient presented again with recurrence of symptoms. It was unclear whether he had had a persistent infection or a separate episode of infection which may or may not be chlamydial. Another blood sample from this patient received 18 months after the second episode showed a low titre of antibodies to $C$ pneumoniae with no detectable $C$ psittaci titre. Case 26 was probably a true $C$ psittaci infection as the micro-IF titre was very high, and the sputum sample was positive for antigen by both ELISA and DIF. 
Discussion

Isolation is frequently taken as the gold standard in microbiological practice. This may not be valid with organisms that are difficult to grow. Of the 20 chlamydial cultures attempted in this series, four isolates were made, of which only three (cases 12, 21, and 22) were definitely identified. Two of these three isolates were $C$ trachomatis. It is recognised that specimen handling procedures used in the study were suboptimal for successful chlamydial cultivation. But the difficulty of isolating $C$ pneumoniae from clinical specimens was well known. ${ }^{6}$ Development of nucleic acid detection by PCR, which does not depend on organism viability, provides an alternative method of diagnosis.

$C$ pneumoniae and $C$ psittaci were the main foci in this PCR study. $C$ trachomatis, which does not commonly cause pneumonia in adults and which is more easily diagnosed by conventional means, was excluded to make the procedure and its interpretation simple. In the procedure described the sputum samples required minimal treatment and no nucleic acid extraction steps were necessary. Mispriming was avoided by adopting the "Touchdown" PCR technique during the first stage. ${ }^{18}$ It was possible to complete the whole procedure within 24 hours by doing one of the PCR stages overnight.

There have been reports of PCR inhibitors being present in faeces, urine and eye swabs. ${ }^{22-24}$ Inhibition was observed in two specimens in this series (cases 11 and 12) during the initial development phase when the specimen preparation procedure consisted only of a single heating step. The inclusion of a proteinase $\mathrm{K}$ digestion step prior to heating removed the inhibitor, indicating its protein nature in these two samples.

Titration studies and comparisons with DIF have suggested that this PCR approach was very sensitive for $C$ pneumoniae. The specificity appeared to be good with high correlation with micro-IF, ELISA, and DIF. Only one of the 10 patients (case 3 ) identified by PCR as $C$ pneumoniae had a history of bird contact, but results from both micro-IF and DIF suggested that the infection was with $C$ pneumoniae rather than $C$ psittaci. The sensitivity of the procedure for $C$ psittaci was inevitably lower due to the strategy chosen. The specificity was good, however, with high micro-IF correlation. There were discrepancies with DIF in two specimens in which DIF identified $C$ pneumoniae; PCR detected $C$ psittaci. Both patients had close bird exposure and micro-IF results supported PCR identification in one of the patients (case 13). On balance, the weight of evidence suggests that DIF may have misidentified the chlamydial species in the sputum deposits of these two patients. This problem of cross-reactivity of the $C$ pneumoniae monoclonal antibody (Cellabs), which may partly be due to the specimen treatment procedure, has been reported before. ${ }^{25}$

Because the detection limit of the first stage PCR was believed to be between five and 10 elementary bodies, cases containing only a few $C$ psittaci elementary bodies in sputa could have been missed. The discrepancy between PCR and ELISA/DIF in cases 23-26 could be explained by this reduced sensitivity. It is believed that PCR was falsely negative for the sputum sample from case 26 . In case 24 only two elementary bodies were detected by DIF in the first sputum smear, although a later specimen was more definitely positive. In case 25 the clinical relevance of the serological findings was indeterminate because serum predated the sputum sample by six months. Prolonged storage, repeated freeze-thaw cycles, and scanty specimens available for testing were other reasons which may have adversely affected PCR sensitivity in some of these samples. On the other hand, as both ELISA and the genus specific DIF used anti-lipopolysaccharide as the detecting antibodies, they could, theoretically, produce similar false positive results.

Both the number of specimens and the design of the study prevented comparison between the performance of ELISA, DIF, and PCR. There were two false positive results by ELISA in this series (cases 19 and 20) and this suggested that direct visualisation of elementary bodies is necessary to confirm all ELISA positive results. However, DIF of sputum smears is difficult to read requiring considerable experience particularly when there are only a few elementary bodies present. Diagnosis of $C$ psittaci by the absence of fluorescence staining with species specific antibodies is unreliable. PCR, however, offers a viable alternative.

PCR, as developed in this study, seemed to be both sensitive and specific for $C$ pneumoniae and also identified $C$ psittaci with good specificity. Improvements in sensitivity for $C$ psittaci can be made by introducing multiplex internal primers which amplify both $C$ pneumoniae and $C$ psittaci in the second stage. The PCR method described can serve as a confirmatory test for screening based on ELISA or DIF. It can also be used as a tool to study the role and prevalence of $C$ pneumoniae in special patient subgroups like asthmatics and those with cystic fibrosis. Further studies could define the role of PCR in routine clinical diagnosis.

This project was conducted with the help of a grant from the Newcastle Health Authority. Dr JD Treharne of the Institute Newcastle Health Authority. Dr J Treharne of the Institute of Ophthalmology, London, kindly provided the various strains of Chlamydiae and performed micro-IF for the study. Professor C R Madeley, the supervisor of this project, and D JSM Peiris, consultant virologist in Royal Victoria Infirmary, Newcastle Upon Tyne have given invaluable advice and guidance.

1 Grayston T, Diwan VK, Cooney M, Wang S-P. Community- and hospital-acquired pneumonia associated with chlamydia TWAR infection dr serologically. Arch Intern Med 1989;149:169-73.

2 Thom DH, Grayston JT, Wang S-P, Kuo C-C, Altman J. Ch DH, Grayston JT, Wang S-P, Kuo C-C, Altman J. Chlamydia pneumoniae strain TWAR, Mycoplasma pneumoniae, and viral infections in acute respiratory disease in a university student he

3 Chirgwin K, Roblin PM, Gelling M, Hammerschlag MR, 
Schachter J. Infection with Chlamydia pneumoniae in Brooklyn. F Infect Dis 1991;163:757-61.

4 Wreghitt TG, Taylor CED. Incidence of respiratory tract chlamydial infections and importation of psittacine birds. Lancet 1988;i:582.

5 Andrews BE, Major R, Palmer SR. Ornithosis in poultry workers. Lancet $1981 ; \mathbf{i}: 632-4$

6 Kuo C-C, Chen H-H, Wang S-P, Grayston JT. Identification of a new group of Chlamydia psittaci strains called TWAR. 7 Clin Microbiol 1986;24:1034-7.

7 Advisory Committee on Dangerous Pathogens. Categorisation of pathogens according to hazard and categories of containment 2nd ed. London: HMSO, 1990.

8 Friis B, Kuo C-C, Wang S-P, Mordhorst CH, Grayston JT. Rapid diagnosis of Chlamydia trachomatis pneumonia in infants. Acta Pathol Microbiol Scand 1984; 92:139-43.

9 Paisley JW, Laver B, Melinkovich P, Glitterman B, Feiten D, Bergman S. Rapid diagnosis of Chlamydia trachomatis pneumonia in infants by direct immunofluorescence microscopy of nasopharyngeal secretions. $\mathcal{F}$ Pediatr 1986;109:653-5.

10 Sillis $M$, White P. Rapid identification of Chlamydia psittaci and TWAR (C. pneumoniae) in sputum samples using an amplified enzyme immunoassay. $f$ Clin Pathol 1990;43:260-62.

11 Hahn DL, Dodge RW. Detection of Chlamydia pneumoniae. Lancet 1991;337:849.

12 Holland SM, Gaydos CA, Quinn TC. Detection and differentiation of Chlamydia trachomatis, Chlamydia psittaci, and Chlamydia pneumoniae

13 Campbell LA, Perez Melgosa M, Hamilton DJ, Kuo C-C, Grayston JT. Detection of Chlamydia pneumoniae by polymerase chain reaction. $\mathcal{f}$ Clin Microbiol 1992;30: 434-9.

14 Kaltenboeck B, Kousoulas KG, Storz J. Two-step polymerase chain reactions and restriction endonuclease analyses detect and differentiate ompA DNA of Chlamydia spp. $f$ Clin Microbiol 1992;30:1098-104.
15 Cater MW, Al-Mahdawi SAH, Giles IG, Treharne JD, Ward ME, Clarke IN. Nucleotide sequence and taxonomic value of the MOMP gene of Chlamydia pneumoniae IOL 207 7 Gen Microbiol 1991;137:465-75.

16 Perez Melgosa M, Kuo C-C, Campbell LA. Sequence analysis of the major outer membrane protein gene of Chlamydia pneumoniae. Infect Immun 1991;59:2195-9.

17 Sillis M, White P, Caul EO, Paul ID, Treharne JD. The differentiation of Chlamydia species by antigen detection in sputum specimens from patients with community-acquired respiratory infections. $\mathcal{f}$ Infect 1992; 25(Suppl 1):77-86.

18 Don RH, Cox PT, Wainwright BJ, Baker K, Mattick JS 'Touchdown' PCR to circumvent spurious priming dur-

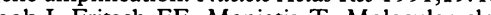

19 Sambrook J, Fritsch EF, Maniatis T. Molecular cloning: A laboratory manual, 2nd edn. New York: Cold Spring Harbor Laboratory Press, 1989.

20 Kwok S, Higuchi R. Avoiding false positives with PCR. Nature. 1989;339:237.

21 Treharne JD, Darougar S, Jones BR. Modification of the microimmunofluorescence test to provide a routine serodiagnostic test for chlamydial infection $f$ Clin Pathol 1977;30:510-17.

22 Wilde J, Eiden J, Yolken R Removal of inhibitory substances from human fecal specimens for detection of group A rotaviruses by reverse transcriptase and polygroup A rotaviruses by reverse transcriptase and poly-
merase chain reactions. $f$ Clin Microbiol 1990;28: merase

23 Khan G, Kangro HO, Coates PJ, Heath RB. Inhibitory effects of urine on the polymerase chain reaction for cytomegalovirus DNA. $f$ Clin Pathol 1991;44:360-5.

24 Bobo L, Munoz B, Viscidi R, Quinn T, Mkocha H, West $\mathrm{S}$. Diagnosis of Chlamydia trachomatis eye infection in Tanzania by polymerase chain reaction/enzyme immunoassay. Lancet 1991;338:847-50.

25 Sillis $M$. Species differentiation in the diagnosis of chlamydial respiratory infection. In Caul EO, ed. Immunofluorescence techniques in diagnostic microbiology. London:PHLS, 1992:90-100. 